\title{
Therapeutic benefits of recombinant alpha1-antitrypsin IgG1 Fc-fusion protein in experimental emphysema
}

\author{
Katsuyuki Takeda ${ }^{1,4^{*}}\left(\mathbb{0}\right.$, Soo-Hyun Kim ${ }^{1,2}$, Anthony Joetham ${ }^{1}$, Irina Petrache ${ }^{3}$ and Erwin W. Gelfand ${ }^{1}$
}

\begin{abstract}
Background: Alpha-1 antitrypsin (AAT) is a major serine protease inhibitor. AAT deficiency (AATD) is a genetic disorder characterized by early-onset severe emphysema. In well-selected AATD patients, therapy with plasma-derived AAT (pAAT), "augmentation therapy", provides modest clinical improvement but is perceived as cumbersome with weekly intravenous infusions. Using mouse models of emphysema, we compared the effects of a recombinant AAT-lgG1 Fcfusion protein (AAT-Fc), which is expected to have a longer half-life following infusion, to those of pAAT.

Methods: In an elastase model of emphysema, mice received a single intratracheal instillation of porcine pancreatic elastase (PPE) or human leucocyte elastase ( $h \mathrm{hE}$ ). AAT-Fc, pAAT, or vehicle was administered intraperitoneally 1 day prior to or 3 weeks following elastase instillation. Lung function and histology assessments were performed at 7 and 32 days after elastase instillation. In a cigarette smoke (CS) model of emphysema, mice were exposed to CS daily, 5 days a week, for 6 months and AAT-Fc, pAAT, or vehicle were administered every 10 days during the last 3 months of CS exposure. Assessments were performed 3 days after the last CS exposure. Immune responses to lung elastin peptide (EP) and the effects of AAT-Fc or pAAT treatment on dendritic cell (DC) function were determined ex vivo.
\end{abstract}

Results: Both elastase instillation and CS exposure triggered emphysema-like alveolar enlargement, increased lung compliance, and increased markers of inflammation compared to controls. Administration of AAT-Fc either prior to or following elastase instillation or during CS exposure provided greater protection than pAAT against alveolar enlargement, lung dysfunction, and airway inflammation. When challenged ex vivo with EP, spleen mononuclear cells from elastase-exposed mice exhibited dose-dependent production of IFNY and IL-17, suggesting immune reactivity. In co-culture experiments with splenic $\mathrm{CD}^{+} \mathrm{T}$ cells isolated from elastase-exposed mice, AAT-Fc treatment prior to EPpriming of bone marrow-derived dendritic cells inhibited the production of IFNY and IL-17.

Conclusions: Compared to PAAT, AAT-Fc more effectively prevented or attenuated elastase- and CS-induced models of emphysema. These effects were associated with immunomodulatory effects on DC activity. AAT-Fc may provide a therapeutic option to individuals with AATD- and CS-induced emphysema.

Keywords: a-1 antitrypsin, Emphysema, Mouse, Elastase, Cigarette smoke, Dendritic cells

*Correspondence: mktakeda@aol.com

1 Division of Cell Biology, Department of Pediatrics, National Jewish Health, Denver, CO, USA

Full list of author information is available at the end of the article

\section{Background}

Alpha-1 antitrypsin (AAT) is a major serine protease plasma inhibitor of neutrophil elastase [1]. In the United States, an estimated at 5.64 million individuals are AATdeficient (AATD) [2]. The main clinical feature of AATD is early-onset emphysema. Exogenous repletion of AAT, "augmentation therapy", is recommended for select original author(s) and the source, provide a link to the Creative Commons licence, and indicate if changes were made. The images or other third party material in this article are included in the article's Creative Commons licence, unless indicated otherwise in a credit line to the material. If material is not included in the article's Creative Commons licence and your intended use is not permitted by statutory regulation or exceeds the permitted use, you will need to obtain permission directly from the copyright holder. To view a copy of this licence, visit http://creativecommons.org/licenses/by/4.0/. The Creative Commons Public Domain Dedication waiver (http://creativeco mmons.org/publicdomain/zero/1.0/) applies to the data made available in this article, unless otherwise stated in a credit line to the data. 
patients with emphysema, with weekly intravenous infusions of AAT purified from pooled human plasma (pAAT) [3, 4]. However, only modest clinical benefits of augmentation therapy have been reported, and these infusions have been associated with side effects related to infusion of high amounts of protein [3, 4]. In addition, augmentation therapy is recognized as inconvenient because of the need for frequent infusions and high costs $[3,5]$. AATD patients with severe and progressive emphysema may require lung transplantation, which carries major risks of morbidity and mortality [5]. Therefore, new therapies for AATD remain a critical unmet need.

In addition to inhibiting elastase, AAT has been shown to act as a potent immunomodulator [1, 6-9]. AAT treatment may be beneficial in various autoimmune diseases such as type-1 diabetes, rheumatoid arthritis, systemic lupus erythematosus, or graft versus host disease in preclinical animal models and clinical studies $[10,11]$. One mechanism by which AAT may exert immunomodulatory effects is through suppression of dendritic cell (DC) function [10].

Compared to pAAT, which is derived from pooled human plasma, AAT-IgG1 Fc-fusion protein (AAT-Fc) is a synthesized recombinant protein. As a synthesized and fusion protein, it would be expected to reduce costs and decrease the risk of adverse events compared to pAAT [12]. The fusion of AAT with Fc is expected to extend the half-life of the protein when compared to pAAT, with comparable levels of elastase inhibition, and prolonging the biologic activity of exogenously administered AAT [13]. Indeed, a similar AAT fused with Fc has been shown to have a longer half-life in serum as well as in the airways compared to pAAT [14]. The Fc portion fused to AAT is also expected to bind to Fc receptors, which are widely expressed on inflammatory cells, including DCs, modulating their activity [15].

To compare the effects of AAT-Fc in preclinical models, two mouse models of emphysema-like disease were used. Because an imbalance in activity between the proteinase and the anti-proteinase (AAT) drives emphysema pathogenesis in AATD [3], an elastase-induced model was applied. In addition, because cigarette smoking is a major risk factor for emphysema in AATD [2], a chronic cigarette smoking (CS) exposure model was also employed. In the elastase-induced models, we used porcine pancreatic elastase (PPE) as well as human leucocyte elastase (hLE). Following a single elastase instillation in mice, emphysematous changes such as alveolar enlargement develop and progress gradually for several months $[16,17]$. To demonstrate the benefits of AAT-Fc, in addition to lung function parameters, elastin autoimmunity and DC function were monitored. Autoimmunity towards lung elastin fragments [18-20] and activation of DCs [21-23] have been shown to contribute to the pathogenesis of emphysema. Using these approaches, we identified the superiority of AAT-Fc compared to pAAT in protecting lung tissue in these experimental models of emphysema.

\section{Methods \\ Animals}

Mice $(\mathrm{C} 57 \mathrm{Bl} / 6)$ were purchased from Jackson Laboratories (Bar Harbor, ME). All mice were housed under specific pathogen-free conditions. Age-matched, equal numbers of male or female mice were used in all experiments. When analyzed by gender, in a multi-way ANOVA, no sex differences were noticed in the results. Experiments were conducted under a protocol approved by the Institutional Animal Care and Use Committee of National Jewish Health.

\section{Development and prevention of elastase-induced emphysema}

To develop elastase-induced emphysema, 6-8-week old male or female mice were anesthetized with isoflurane and PPE was instilled via the trachea. PPE (120 U/kg) (Elastin Products Company, Owensville, MO) was dissolved in $40 \mu \mathrm{L}$ of physiological saline solution (saline) prior to instillation. PPE was instilled once, as it was previously demonstrated by us and by other laboratories that a single PPE intratracheal instillation with this dose led to significant emphysematous changes in the lungs of mice $[15,24]$. In some experiments, hLE $(700 \mathrm{U} / \mathrm{kg})$ (Elastin Products Company) was used. Control mice received saline alone. Seven, 21, or 32 days after elastase administration, lung function was measured. Briefly, mice received an overdose of pentobarbital by intraperitoneal (i.p.) injection and the inserted tracheal cannula was attached to a FlexiVent system (Scireq, Montreal, Canada) to ventilate and analyze lung function. Pressure-volume curves were generated and static compliance (Cst) and total lung capacity (TLC) were calculated using FlexiVent software.

After lung function measurements, lung tissues were collected following inflation at constant pressure (15 $\mathrm{cmH}_{2} \mathrm{O}$ for $10 \mathrm{~min}$ ) with $10 \%$ buffered formalin for further morphometric analyses to determine the degree of emphysematous changes. Slides of left lung tissue were stained with hematoxylin-eosin and analyzed for mean linear intercept (MLI) according to the guidelines of the American Thoracic Society/European Respiratory Society [25]. The slide images of an entire lung section excluding airways and vessels were captured using a microscope (BX40; Olympus America, Melville, NY) equipped with a digital camera (Q-color 3; Olympus America, Center Valley, PA). Mean-free distance was quantified as MLI in 
the captured images by randomly set test lines using $\mathrm{NIH}$ Image J software (available at http://imagej.nih.gov/ij/ download.html). Values of alveolar surface area (S) were also calculated with MLI and TLC as described previously [26]. Bronchoalveolar lavage (BAL) was performed with $1 \mathrm{~mL}$ of Hanks' balanced salt solution in a subset of mice after airway function measurements but prior to lung tissue sampling, and cells in BAL fluid were counted and differentiated as described previously [27].

\section{CS-induced emphysema}

Eight-week old male or female mice were exposed to whole smoke generated from research grade 3R4F cigarettes (Univ. of Kentucky) using the TE-10 smoking chamber (Teague Enterprises, Davis, CA). The machine was adjusted to generate a mixture of side-stream smoke (89\%) and mainstream smoke (11\%). Chamber atmosphere was monitored for total suspended particulates with concentrations of $90-110 \mathrm{mg} / \mathrm{m}^{3}$, respectively. Control mice were kept in a filtered air environment. Mice received CS continuously for $5 \mathrm{~h}$ /day, 5 days/week for 6 months. Three days after the last CS exposure, analyses of lung function and lung morphometry were performed as described for the elastase-induced emphysema model.

\section{Reagents preparation}

AAT-Fc was purchased from YBDY Biotechnology (Seoul, Korea). AAT-Fc was generated by expressing recombinant AAT and fusing the intact AAT gene to the constant region of IgG1 to generate soluble recombinant AAT-Fc protein. The recombinant AAT-Fc protein was produced in Chinese hamster ovary cells and purified using mini-protein A affinity chromatography [28]. According to the manufacturer's catalogue, the purity of AAT-Fc was $90 \%$. Two $\mathrm{mg} / \mathrm{kg}$ (body weight) of AAT-Fc was dissolved in $200 \mu \mathrm{l}$ of PBS and administered by i.p. injection. Other groups of mice received $2 \mathrm{mg} / \mathrm{kg}$ of pAAT (Prolastin C; Grifols USA, Los Angeles, CA), $2 \mathrm{mg} / \mathrm{kg}$ of recombinant human IgG Fc (EMD Millipore, Billerica, MA), or PBS as a vehicle by i.p. injection. Mice received treatments 1 day prior to or 21 days after elastase instillation. In CS-exposure experiments, mice received $2 \mathrm{mg} / \mathrm{kg}$ of AAT-Fc, pAAT, IgG Fc, or vehicle alone by i.p. injection every 10 days during the last 3 months of CS exposure. As the anti-proteinase activity of AAT was expected to prevent elastase-induced lung tissue damage when administered prior to elastase instillation, IgG Fc was not used as a control in this set of experiments.

\section{Preparation of spleen cells}

To determine immune responses against lung elastin, spleen mononuclear cells (MNCs) from PPE-treated mice on day 21 were isolated by Histopaque 1083 (Sigma-Aldrich, St. Louis, MO) as described previously [26]. Cells were washed, counted, and suspended in complete RPMI 1640 tissue culture medium (Mediatech Celgro, Manassas, VA), containing heat-inactivated fetal calf serum (FCS 10\%; Sigma), L-glutamine (5 mM), $\alpha$-mercaptoethanol (2 mM), Hepes buffer $(15 \mathrm{mM})$, penicillin (100 units/ml), and streptomycin $(100 \mu \mathrm{g} / \mathrm{ml})$ (all from Invitrogen). Cells $\left(8 \times 10^{6} / \mathrm{mL}\right)$ were cultured with 2,10 , or $50 \mu \mathrm{g} / \mathrm{mL}$ mouse lung elastin peptide (EP, Elastin Products Company) for 4 days and IFNy and IL-17 levels in culture supernatants were measured by ELISA (eBioscience, San Diego, CA).

\section{AAT-Fc treatment effects on dendritic cells}

DCs were derived from bone marrow of naive mice following culture with $10 \mathrm{ng} / \mathrm{mL}$ of mouse GM-CSF and IL-4 (both from Peprotech, Rocky Hill, NJ) for 1 week as described previously [29]. Cultured cells were identified as DCs; cell surface expression of CD11c and MHC Class II was greater than $98 \%$. DCs $\left(4 \times 10^{4}\right.$ cells $)$ were suspended in RPMI culture medium and treated with 1,10 , or $100 \mu \mathrm{m}$ of AAT-Fc or pAAT. Twenty-four hours later, DCs were washed and cultured with mouse lung elastin peptide $(50 \mu \mathrm{g} / \mathrm{mL})$. Following treatment with PPE, on day $21 \mathrm{CD}^{+}$or $\mathrm{CD}^{+} \mathrm{T}$ cells were purified from spleen cells with magnetic beads (EasySep, STEMCELL Technologies, Vancouver, Canada) and $4 \times 10^{5}$ purified $\mathrm{CD}_{4}^{+}$ or $\mathrm{CD}^{+} \mathrm{T}$ cells were co-cultured with prepared DCs.

\section{Statistical analysis}

Values for all measurements were expressed as means \pm SEM. For comparisons between multiple groups, the Tukey-Kramer test was used. Nonparametric analyses, using the Mann-Whitney U test or KruskalWallis test, were also applied to confirm that statistical differences remained significant, even if the underlying distribution was uncertain. The $p$-value for significance was set at less than 0.05 .

\section{Results}

Effect of AAT-Fc administration prior to elastase instillation To investigate preventative effects, AAT-Fc or pAAT was administered prior to elastase instillation followed 1 week later by lung analyses (Fig. 1A). PPE instillation significantly increased granulocytic inflammation in BAL fluid and resulted in airspace enlargement with disruption of alveolar walls, as determined by increased Cst and MLI and decreased S values (Fig. 1B-E). AATFc or pAAT treatment significantly reduced numbers of granulocytes by $56 \%$ and $40 \%$ respectively in the BAL fluid of PPE-instilled mice (Fig. 1F). Unlike pAAT administration, AAT-Fc treatment prior to PPE 


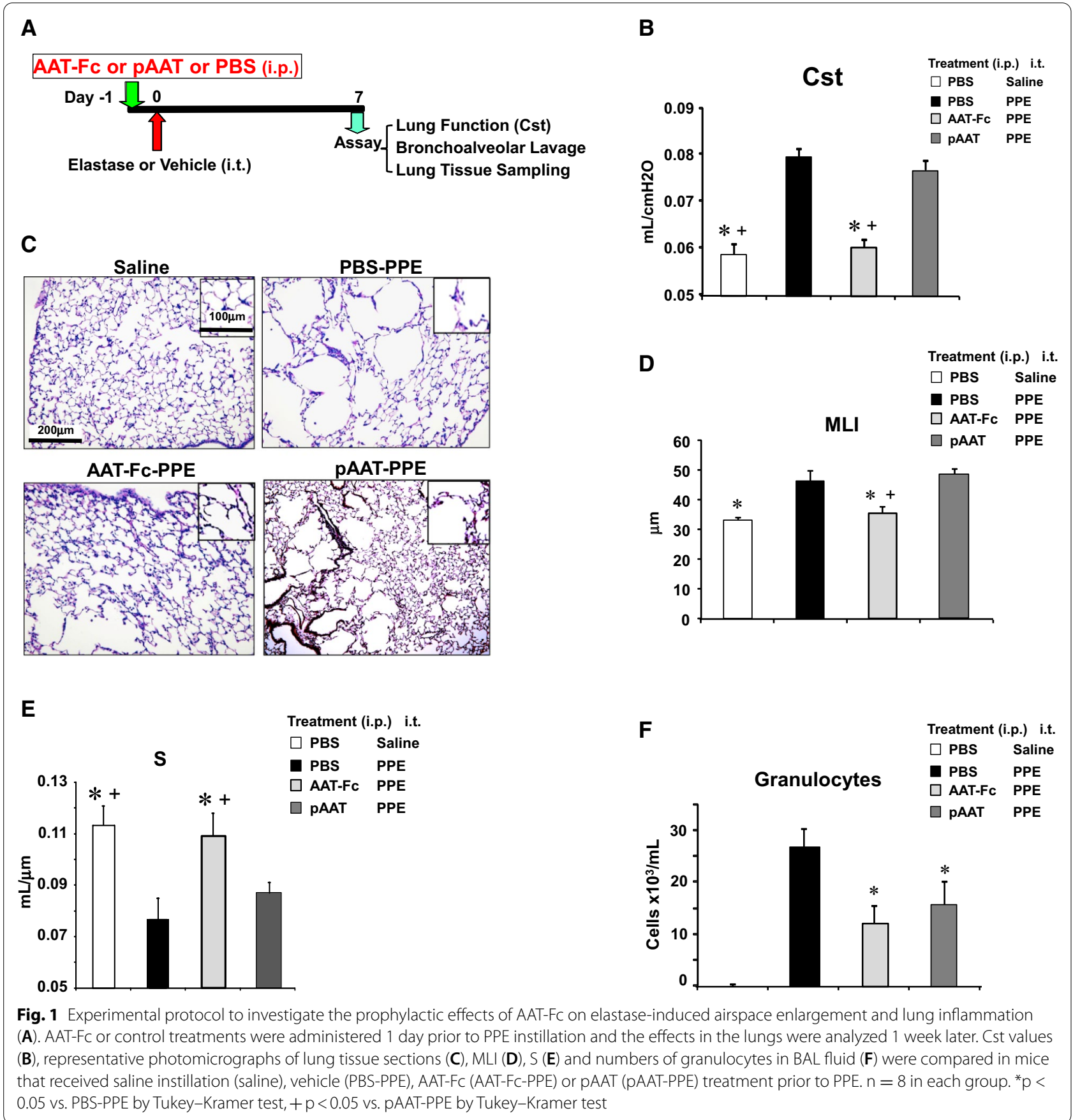

instillation significantly inhibited alveolar enlargement (24\% decrease in MLI and 30\% increase in S values) and lung dysfunction (23\% decrease in Cst) induced by elastase (Fig. 1B-E). hLE instillation induced more modest airway inflammation (data not shown) but caused alveolar enlargement with increased MLI and decreased $\mathrm{S}$ values and increased Cst. Pretreatment with AAT-Fc, but not pAAT prevented the development of airspace enlargement following hLE instillation (Additional file 1: Figure S1).

\section{Effect of AAT-Fc aministration following elastase instillation}

To investigate the effect of treatment when administered after the onset of lung injury, AAT-Fc, pAAT, or controls were administered 21 days after a single PPE 
instillation (Fig. 2A). At 21 days after PPE instillation and then 11 days after treatment (day 32 following PPE), lung function and histopathological analyses were performed. As shown in Fig. 2B-E, at day 21 after a single PPE instillation, lung pathology and alveolar enlargement were clearly evident. When analyses were carried out on day 32 , the administration of AAT-Fc (on day 21) significantly decreased Cst and MLI values and increased $\mathrm{S}$ values (15\% and $35 \%$ decrease and $18 \%$ increase, respectively) compared with vehicle treatment, and these effects were significantly more pronounced than following pAAT or IgG1-Fc treatment. Moreover, only AAT-Fc treatment improved lung dysfunction (10\% improvement in Cst and 30\% improvement in MLI and increased values of $8 \%)$ compared to day 21 values following PPE instillation. These data suggested that AAT-Fc treatment not only attenuated the progression of lung damage, but reversed the pathologic events initiated by PPE.

\section{A}

\section{Experimental Protocol}

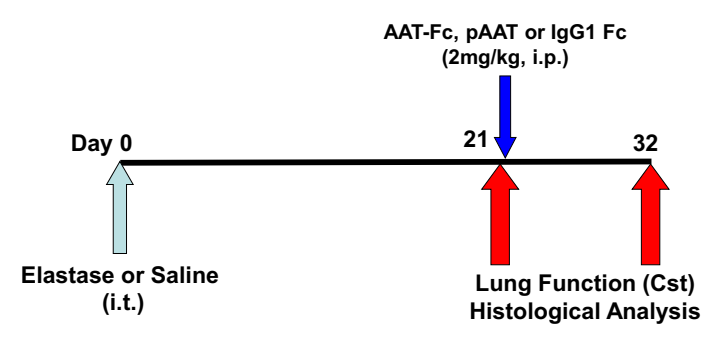

C
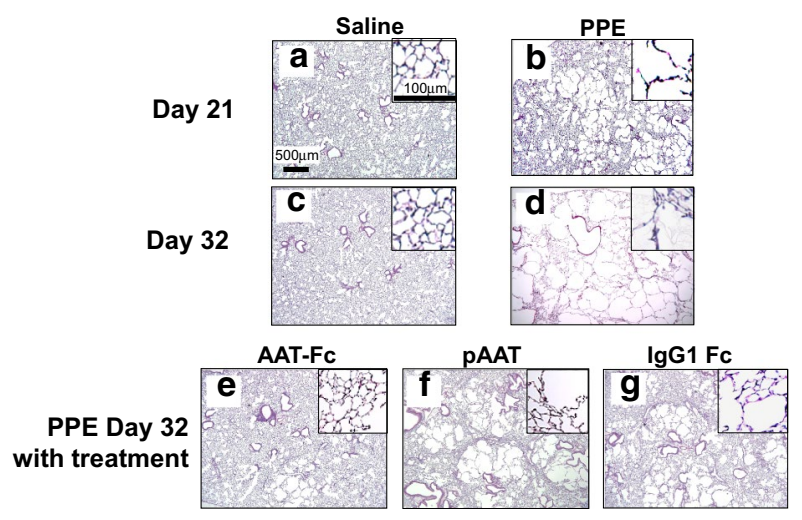

E

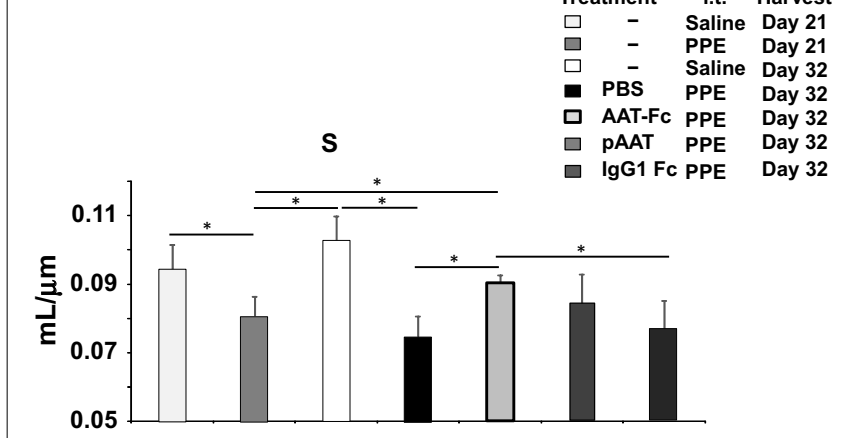

B

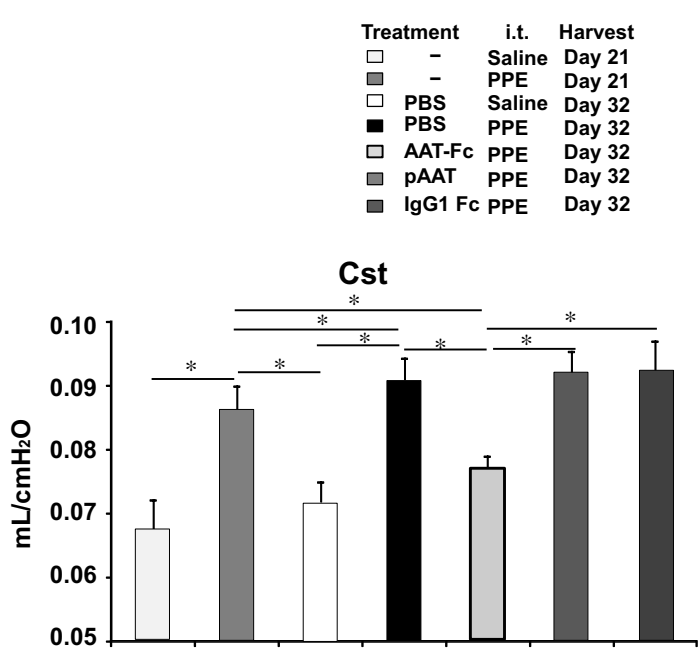

D
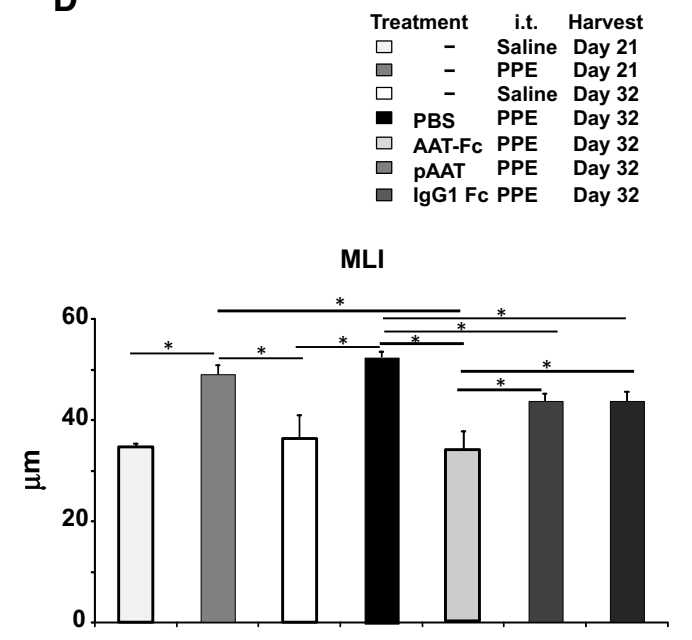

Fig. 2 Experimental protocol to assess the effects of AAT-Fc following elastase instillation (A). Mice received AAT-Fc, pAAT, IgG1-Fc or vehicle 21 days after PPE instillation and the effects in the lungs were analyzed 32 days after PPE (AAT FC PPE day 32, PAAT PPE day 32, IgG1-FC PPE day 32, and PBS PPE day 32, respectively). A control group received saline instillation and lungs were analyzed 32 days later. Separate groups of mice were analyzed 21 days after saline or PPE instillation without any treatment (saline day 21 and PPE day 21, respectively). Cst values (B), lung tissue sections (C), MLI (D), and alveolar surface area (S) (E) values were compared. $n=8$ in each group. ${ }^{*} p<0.05$ by Tukey-Kramer test 
Effect of AAT-Fc treatment on CS-induced emphysema Mice received AAT-Fc, pAAT, IgG1-Fc, or PBS as a vehicle control every 10 days during the last 3 months of the 6-month CS exposure (Fig. 3A). Lung function testing in CS-exposed mice revealed significant reductions in Cst following treatment with AAT-Fc (14\% increase) but not following pAAT or IgG1-Fc treatment which were similar to vehicle treatment (Fig. 3B). Histopathological analyses demonstrated significant improvements in destruction of alveolar septa, MLI and S values following AAT-Fc treatment ( $40 \%$ decrease and $48 \%$ increase, respectively), but not following pAAT or IgG1-Fc treatments (Fig. 3C-E).

\section{Effect of AAT-Fc treatment on elastin autoimmunity and DC function}

Despite transient enzymatic activity of PPE following intratracheal instillation [30], alveolar enlargement progressed for several months $[16,17]$. The sustained lung destruction may be explained by autoimmunity towards lung tissue components such as EP which is induced by elastase. In a first set experiments, immune responses towards EP in spleen MNCs were determined in vitro. As shown in Fig. 4A, IFN $\gamma$ and IL-17 levels were increased following incubation of spleen MNCs with EP. These increases in cytokine levels were only seen following incubation of spleen MNCs from PPE-treated mice (data not shown), implying that a subset of spleen MNCs from PPE-treated mice developed an immune response to EP.

In light of the suggested immune response to EP and the importance of DC antigen-presentation, in a second set of experiments, bone marrow-derived DCs were treated with AAT-Fc or pAAT prior to EP exposure and co-cultured with spleen $\mathrm{CD}^{+}{ }^{+} \mathrm{T}$ cells isolated from mice that received PPE. As shown in Fig. 4B, spleen $\mathrm{CD} 4^{+}$ $\mathrm{T}$ cells co-cultured with EP-primed DCs resulted in increased levels of IFNY or IL-17 production. These levels were decreased following co-culture of these $\mathrm{CD}^{+}$ $\mathrm{T}$ cells with EP-primed DCs which were pretreated with AAT-Fc or pAAT compared to co-culturing with EPprimed DCs pre-treated with vehicle. The inhibitory
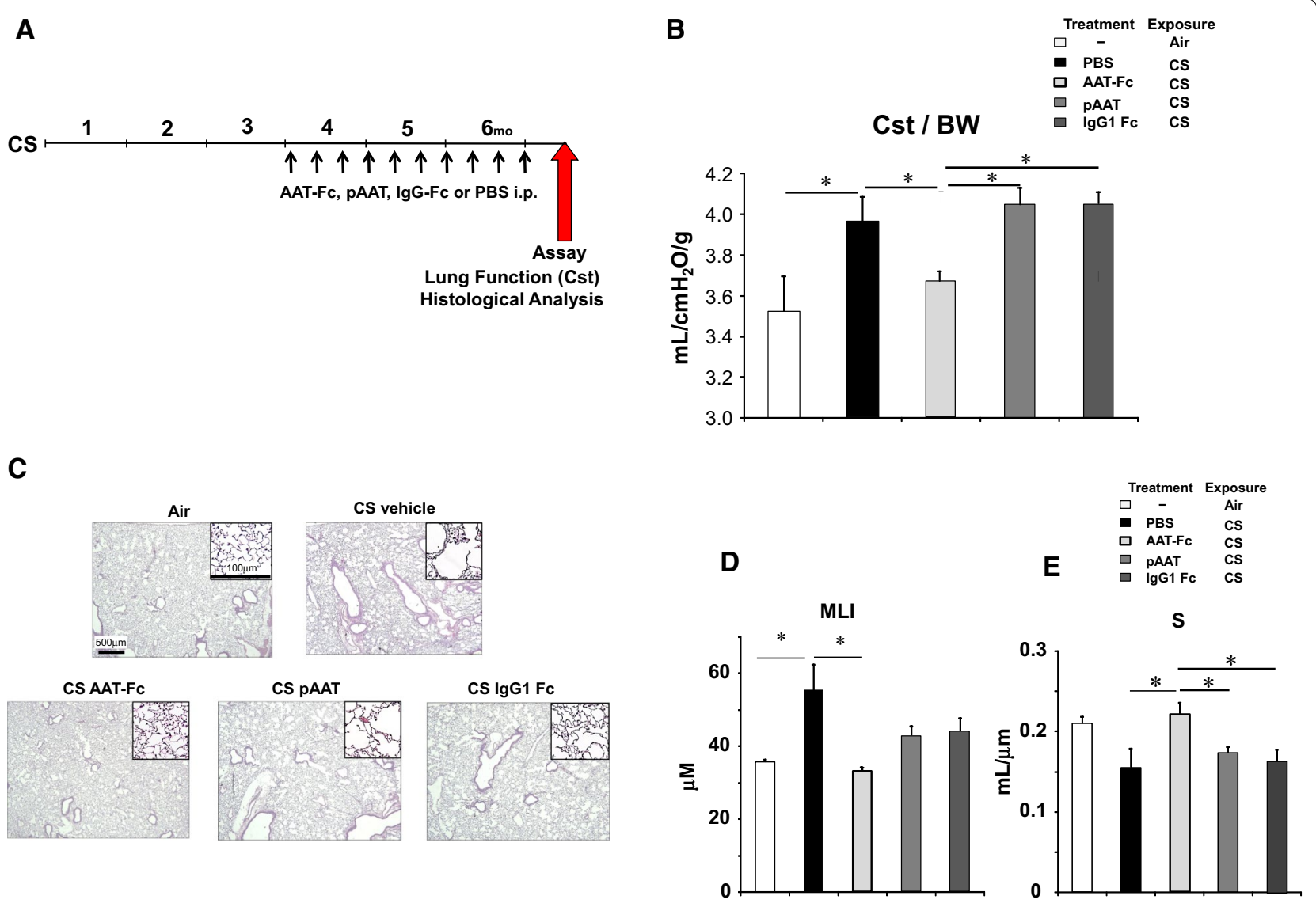

Fig. 3 Experimental protocol to assess the effects of AAT-FC following cigarette smoke exposure (A). During the last 3 months of 6-month long CS exposure, mice received AAT-Fc, pAAT, IgG1-Fc, or PBS as a vehicle control every 10 days (CS AAT-FC, CS pAAT, CS IgG1-FC, or CS vehicle, respectively). A control group of mice were exposed to ambient air (Air). Cst values (B), lung tissue sections (C), MLI (D), and alveolar surface area (S) (E) values were compared between each group of mice. $n=8$ in each group. ${ }^{*} p<0.05$ by Tukey-Kramer test 


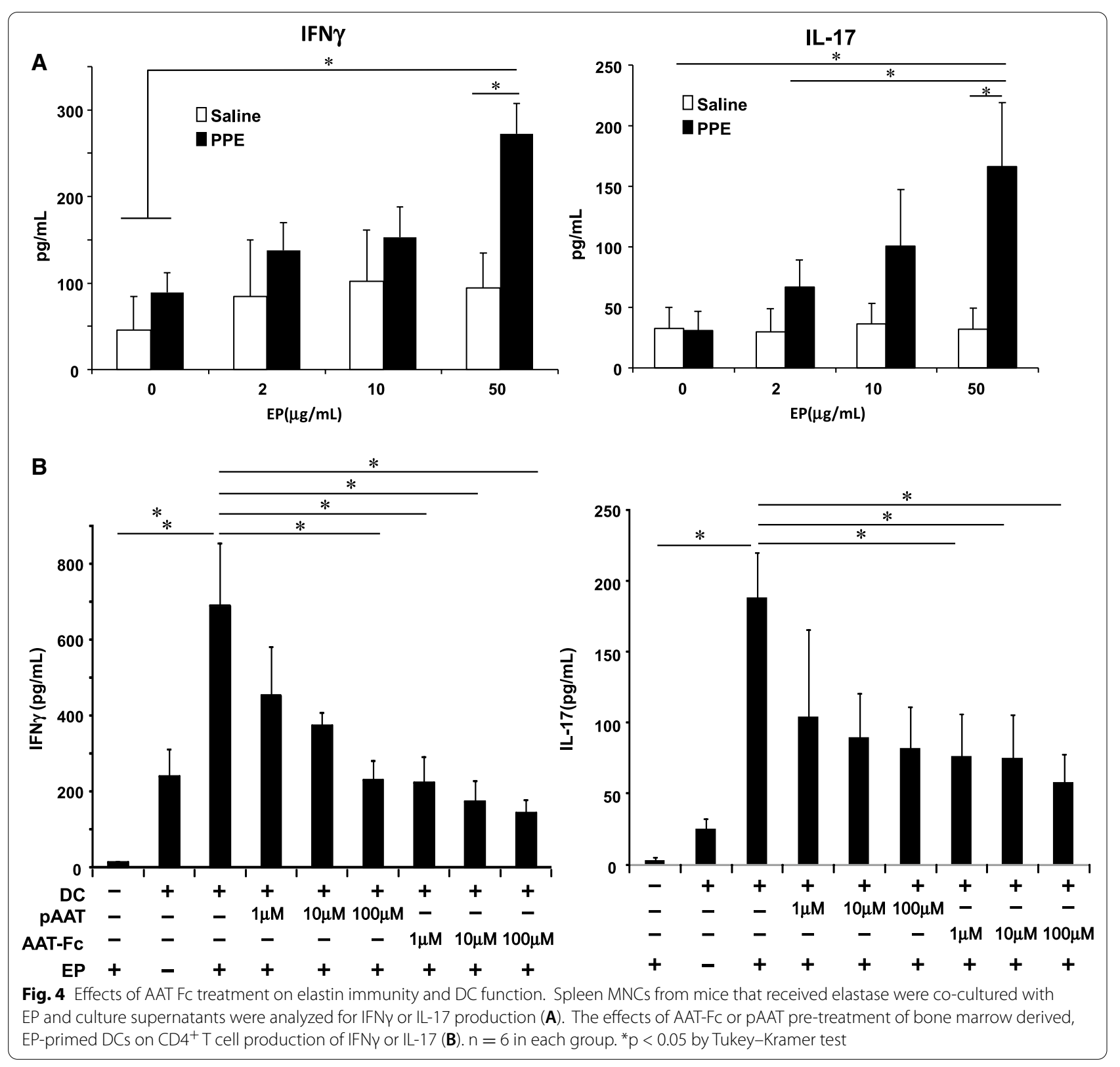

effects of AAT-Fc treatment on DCs were greater than those on pAAT-treated DCs. Co-culturing of $\mathrm{CD}^{+}$ $\mathrm{T}$ cells from PPE-treated mice with DCs showed no increases in IFN $\gamma$ or IL-17 production (data not shown).

\section{Discussion}

In the present study, the therapeutic benefits of recombinant AAT-Fc treatment in two experimental models of emphysema were investigated and compared to effects seen following plasma-derived, pAAT treatment. Beneficial effects were demonstrated at two stages of elastaseinduced lung damage, either when administered prior to elastase instillation, suggesting prophylactic activity, and when administered after elastase, with attenuation of progression of lung injury accompanied by reversal of existing damage. AAT-Fc treatment prior to PPE instillation inhibited the development of airway inflammation and increases in airspace enlargement, both physiologically and morphologically. AAT-Fc also showed protective effects on lung tissue damage following human elastase instillation. When treatments were initiated three weeks after PPE instillation, AAT-Fc not only reduced parameters correlating with airspace enlargement, but returned these parameters to their near-normal state. 
In all aspects, the effects of AAT-Fc were greater than those seen with pAAT or control, IgG1-Fc. The benefits of AAT-Fc treatment were also shown in CS-exposed mice with improvements in airspace enlargement. Spleen MNCs isolated from PPE-treated mice and exposed to EP produced IFN $\gamma$ and IL-17. In these studies, the inhibitory effects of AAT-Fc on cytokine production were shown to reside on EP primed-DCs when co-cultured with $\mathrm{CD}_{4}^{+}$ T cells.

Intravenous augmentation therapy with pAAT has, to date, been the only specific treatment for AATD patients with advanced emphysema [3, 4]. However, studies revealed only modest effects of this therapy; this treatment slowed progression of emphysema as measured by lung density with computed tomography or total lung capacity, but not when measured by functional residual capacity [31]. Following a single administration of PPE or hLE, we demonstrated the prophylactic effects of AATFc on airway inflammation and alveolar enlargement, whereas pAAT failed to prevent alveolar enlargement. As damage of lung tissue at an early time-point following elastase instillation is thought to be induced by proteinase activity, these results support potent anti-protease activities of AAT-Fc in the prevention of elastase-induced lung damage.

Similar robust beneficial effects of AAT, especially with AAT-Fc, were seen in our model of CS-exposure. AAT treatment has been shown to be beneficial in other mouse models of emphysema, including those induced by vascular endothelial growth factor receptor blockade [32] or by CS exposure. Relatively high doses of pAAT $(1000 \mathrm{mg} / \mathrm{kg})$ throughout 6 months of CS exposure resulted in a $63 \%$ improvement in airspace size and abolished CS-induced plasma tumor necrosis factor(TNF)- $\alpha$ increases [33]. In our study, a dose of $2 \mathrm{mg} / \mathrm{kg}$ of AAT-Fc and pAAT was administered, as this dosage of AAT-Fc showed effects in a previous study in mice [12]. A separate study showed that recombinant AAT administered by inhalation for 6 months prior to each day of CS exposure resulted in up to $73 \%$ reduction in airspace enlargement [34]. Smoking is a primary cause of emphysema in COPD and AATD patients, although only a subset of smokers develops COPD or emphysema $[35,36]$. A variety of theories has been proposed to explain the underlying disease pathophysiology and include genetic susceptibility and exposure to poor ambient air quality at early ages [37]. Immune responses against components of lung tissue have been implicated [38]. Oligoclonal expansion of CD4 ${ }^{+} \mathrm{T}$ cells in lung tissue of emphysema patients has been shown [39] and immune responses against elastin as a component of lung tissue have been supported by increased production levels of IFNy from peripheral blood CD4.
$\mathrm{T}$ cells in COPD patients [40]. Increases in IFN $\gamma$ - and IL-6-producing blood $\mathrm{T}$ cells to elastin fragments had a positive association with the annual rate of emphysema progression in active smokers [41]. In addition, B-cells were up-regulated in patients with emphysema [42]. Such autoimmune responses towards lung tissue components are proposed to be a part of the pathogenesis of COPD and emphysema [20]. The findings that lung inflammation continues and lung damage progresses despite smoking cessation in severe cases of emphysema may support this notion of self-destructive processes [39]. The ongoing lung tissue damage after a single elastase administration also implicated autoimmune mechanisms, especially immunity against elastin fragments. Indeed, antagonizing elastin fragments inhibited the development of PPE-induced alveolar enlargement in mice [43].

A number of effects of pAAT were demonstrated in animal models beyond simple AAT replacement and restoration of anti-proteinase therapy with demonstrable anti-inflammatory and immunomodulatory activities. pAAT administration with a carrier lipoprotein prior to and following PPE instillation prevented increases in IL-6, monocyte chemoattractant protein 1 , TNF- $\alpha$, matrix metalloproteinase- 2 and -9 , fibronectin levels, and MLI [44]. An important target may be DCs as these cells are thought to play a role in the pathogenesis of COPD and emphysema [45]. DC numbers were increased in the small airways of COPD patients and the numbers were associated with disease severity [46-48]. Expression levels of the costimulatory molecule, CD83, on DCs in the lungs of COPD patients were also associated with disease severity [47, 48]. In animal models, DC activities were upregulated in PPE-induced [49] and CS-induced emphysema models, and following in vitro CS exposure [50-53]. pAAT treatment has been shown to modulate DC function with decreased MHC class II, CD40, and CD86 expression, reduced IL-6 release, and increased production of IL-10 [6]. pAAT treatment also inhibited LPS- and CpG-induced activation of DCs and reduced the production of inflammatory cytokines [54]. pAAT treatment altered DC function to become tolerogenic, whereas isolated $\mathrm{T}$ cell activities were not altered by pAAT treatment [55].

We determined the effects of AAT-Fc or pAAT on the antigen-presenting function of EP-primed bone marrowderived DCs by determining their role in elastin-induced cytokine production following co-culture with spleen $\mathrm{CD}^{+}$(and $\mathrm{CD}^{+}$) $\mathrm{T}$ cells derived from PPE-treated mice. $\mathrm{CD}^{+}{ }^{+} \mathrm{T}$ cells from PPE-treated mice produced IFN $\gamma$ and IL-17 following co-culture with EP-primed DCs. When $\mathrm{CD}^{+}{ }^{+} \mathrm{T}$ cells were co-cultured with AAT-Fc treated DCs, cytokine production levels were decreased; cytokine 
production was less affected if the DCs were treated with pAAT.

Peptide-Fc fusion proteins are generated by fusing a biologically active peptide with the Fc-domain of immunoglobulin G to extend the half-life [13]. This is the result of the binding to the neonatal $\mathrm{Fc}$ receptor $(\mathrm{Fc} \gamma \mathrm{Rn})$ as Fc $\gamma R n$ is thought to protect their ligands [56]. In addition, the Fc portion of fused protein potently binds to $\mathrm{Fc} \gamma$ receptors which are expressed on many immune cells and modulate activities of these cells [13]. DCs also express Fcy receptors and FcyRn [57]. Thus, AAT-Fc may be expected to promote desirable target cell binding and induce immunomodulatory activities more efficiently on immune cells, including DCs, compared to pAAT. An imbalance between protease and anti-protease activities is thought to be a primary mechanism in the pathogenesis of COPD including emphysema in AAT-sufficient patients (58). In light of the superior benefits of recombinant AAT-Fc over pAAT, the associated costs of pAAT vs. AAT-Fc, and the longer half-life of AAT-Fc, further development of AAT-Fc as a therapeutic tool in AATdeficient and AAT-sufficient emphysema is warranted.

\section{Conclusions}

We demonstrated the potent and superior therapeutic effects of AAT-Fc in elastase- and CS-induced models of emphysema when compared to pAAT. These effects were associated with immunomodulatory effects on DC activity. AAT-Fc may provide a therapeutic option to individuals with AATD- and CS-induced emphysema. Determining the clinical benefits of AAT-Fc in emphysema patients is warranted.

\section{Abbreviations}

AAT: Alpha-1 antitrypsin; AATD: Alpha-1 antitrypsin deficiency; AAT-Fc: Alpha-1 antitrypsin-IgG1 FC-fusion protein; BAL: Bronchoalveolar lavage; CS: Cigarette smoke; Cst: Static compliance; EP: Elastin peptide; hLE: Human leucocyte elastase; i.p.: Intraperitoneal; MLI: Mean linear intercept; MNCs: Mononuclear cells; PAAT: Human plasma-derived alpha-1 antitrypsin; PPE: Porcine pancreatic elastase; Saline: Physiological saline solution; S: Alveolar surface area; TLC: Total lung capacity.

\section{Supplementary Information}

The online version contains supplementary material available at https://doi. org/10.1186/s12931-021-01784-y.

Additional file 1: Figure S1. AAT-Fc or control treatments were administered 1 day prior to hLE instillation and the effects in the lungs were analyzed 1 week later. Cst values (A), MLI (B), and S (C) were compared in mice that received saline instillation (saline), vehicle (PBS-PPE), AAT-FC (AAT-Fc-PPE), or PAAT (pAAT-PPE) treatment prior to hLE. $n=8$ in each group. ${ }^{*} p<0.05$ by Tukey-Kramer test.

\section{Acknowledgements}

The authors thank Diana Nabighian for assistance in preparing the manuscript.

\section{Authors' contributions}

KT, IP, EWG: contributed to acquisition of data, data analysis and interpretation, and preparation of the manuscript. SHK, AJ: contributed to design of study and acquisition of data. All authors agreed to be accountable for all aspects of the work. All authors have read and approved the final manuscript.

\section{Funding}

This research was supported by the Eugene F. and Easton M. Crawford Charitable Lead Unitrust (to E.W.G.), the Dreiseszun Family Foundation (to E.W.G.), and the Alpha-1 Foundation Research Grant (to K.T.).

\section{Availability of data and materials}

All data generated or analyzed during this study are included in this published article and its supplementary information files. The datasets used and/or analyzed during the current study are available from the corresponding author on request.

\section{Declarations}

Ethics approval and consent to participate

All experiments involving animals were in accordance with the Guide for the Care and Use of Laboratory Animals and approved by the Institutional Animal Care and Committee of National Jewish Health (Approved Numbers: AS279902-18 and AS2799-01-21), which is accredited by the AAALAC.

\section{Consent for publication}

Not applicable.

\section{Competing interests}

The authors declare that they have no competing interests.

\section{Author details}

${ }^{1}$ Division of Cell Biology, Department of Pediatrics, National Jewish Health, Denver, CO, USA. ${ }^{2}$ College of Veterinary Medicine, Konkuk University, Seoul, South Korea. ${ }^{3}$ Division of Pulmonary, Critical Care \& Sleep Medicine, Department of Medicine, National Jewish Health, Denver, CO, USA. ${ }^{4}$ Kyoritsu-Onsen Hospital, 1-39-1 Hirano, Kawanishi 666-0121, Japan.

Received: 28 January 2021 Accepted: 24 June 2021

Published online: 16 July 2021

\section{References}

1. de Serres F, Blanco I. Role of alpha-1 antitrypsin in human health and disease. J Intern Med. 2014;276:311-35.

2. Hatipoğlu U, Stoller JK. a1-antitrypsin deficiency. Clin Chest Med. 2016;37:487-504.

3. Brantly ML, Lascano JE, Shahmohammadi A. Intravenous alpha-1 antitrypsin therapy for alpha-1 antitrypsin deficiency: the current state of the evidence. Chronic Obstr Pulm Dis. 2018;6:100-14.

4. López-Campos JL, Carrasco Hernandez L, Caballero EC. Implications of a change of paradigm in alpha1 antitrypsin deficiency augmentation therapy: from biochemical to clinical efficacy. J Clin Med. 2020;9:2526.

5. Hartert M, Senbaklavacin O, Gohrbandt B, Fischer BM, Buhl R, Vahld CF. Lung transplantation: a treatment option in end-stage lung disease. Dtsch Arztebl Int. 2014;111:107-16.

6. Ozeri E, Mizrahi M, Shahaf G, Lewis EC. a-1 antitrypsin promotes semimature, IL-10-producing and readily migrating tolerogenic dendritic cells. J Immunol. 2012;189:146-53.

7. Gottlieb PA, Alkanani AK, Michels AW, Lewis EC, Shapiro L, Dinarello CA, et al. a1-antitrypsin therapy downregulates toll-like receptor-induced $\mathrm{LL}-1 \beta$ responses in monocytes and myeloid dendritic cells and may improve islet function in recently diagnosed patients with type 1 diabetes. J Clin Endocrinol Metab. 2014;99:E1418-26.

8. Strange C, Beiko T. Treatment of alpha-1 antitrypsin deficiency. Semin Respir Crit Care Med. 2015;36:470-7.

9. Stockley RA. The multiple facets of alpha-1-antitrypsin. Ann Transl Med. 2015;3:130. 
10. Lewis EC. Expanding the clinical indications for a(1)-antitrypsin therapy. Mol Med. 2012;18:957-70.

11. Song S. Alpha-1 Antitrypsin therapy for autoimmune disorders. Chronic Obstr Pulm Dis. 2018;5:289-301.

12. Lee S, Lee Y, Hong K, Hong J, Bae S, Choi J, et al. Effect of recombinant a1-antitrypsin Fc-fused (AAT-Fc) protein on the inhibition of inflammatory cytokine production and streptozotocin-induced diabetes. Mol Med. 2013;19:65-71.

13. Levin D, Golding B, Strome SE, Sauna ZE. Fc fusion as a platform technology: potential for modulating immunogenicity. Trends Biotechnol. 2015:33:27-34.

14. United States Securities and Exchange Commission. "INBRX-101", In: Amendment No. 1 To Form S-1 Registration Statement 2019. INHIBRX, INC. https://basic.10jqka.com.cn/ajax/usaph/pubDetail/e0567a4b28 209ff6_html. Accessed 3 May 2021.

15. Guilliams M, Bruhns P, Saeys Y, Hammad H, Lambrecht BN. The function of FCY receptors in dendritic cells and macrophages. Nat Rev Immunol. 2014;14:94-108

16. Tibboel J, Keijzer R, Reiss I, de Jongste JC, Post M. Intravenous and intratracheal mesenchymal stromal cell injection in a mouse model of pulmonary emphysema. COPD. 2014;11:310-8.

17. Limjunyawong N, Craig JM, Lagassé HA, Scott AL, Mitzner W. Experimental progressive emphysema in BALB/CJ mice as a model for chronic alveolar destruction in humans. Am J Physiol Lung Cell Mol Physiol. 2015;309:L662-76.

18. Bhavani S, Yuan X, You R, Shan M, Corry D, Kheradmand F. Loss of peripheral tolerance in emphysema Phenotypes, exacerbations, and disease progression. Ann Am Thorac Soc. 2015;12(Suppl 2):S164-8.

19. Sellami M, Meghraoui-Kheddar A, Terryn C, Fichel C, Bouland N, Diebold $M D$, et al. Induction and regulation of murine emphysema by elastin peptides. Am J Physiol Lung Cell Mol Physiol. 2016;310:L8-23.

20. Caramori G, Ruggeri P, Di Stefano A, Mumby S, Girbino G, Adcock IM, et al. Autoimmunity and COPD: Clinical implications. Chest. 2018;153:1424-31.

21. Botelho FM, Nikota JK, Bauer CM, Morissette MC, Iwakura Y, Kolbeck R, et al. Cigarette smoke-induced accumulation of lung dendritic cells is interleukin-1 a-dependent in mice. Respir Res. 2012;13:81.

22. Stoll P, Ulrich M, Bratke K, Garbe K, Virchow JC, Lommatzsch M. Imbalance of dendritic cell co-stimulation in COPD. Respir Res. 2015;16:19.

23. Liang Y, Shen Y, Kuang L, Zhou G, Zhang L, Zhong X, et al. Cigarette smoke exposure promotes differentiation of CD4(+)T cells toward Th17 cells by CD40-CD40L costimulatory pathway in mice. Int J Chron Obstruct Pulmon Dis. 2018:13:959-68.

24. Takeda K, Ning F, Domenico J, Okamoto M, Ashino S, Kim SH, et al. Activation of p70S6 kinase-1 in mesenchymal stem cells is essential to lung tissue repair. Stem Cells Transl Med. 2018;7:551-8.

25. Hsia CC, Hyde DM, Ochs M, Weibel ER, ATS/ERS Joint Task Force on Quantitative Assessment of Lung Structure. An official research policy statement of the American Thoracic Society/European Respiratory Society: standards for quantitative assessment of lung structure. Am J Respir Crit Care Med 2010;181:394-418.

26. Mitzner W. Use of mean airspace chord length to assess emphysema. J Appl Physiol. 2008;105:1980-1.

27. Ashino S, Takeda K, Li H, Taylor V, Joetham A, Pine PR, et al. Janus kinase $1 / 3$ signaling pathways are key initiators of $\mathrm{TH} 2$ differentiation and lung allergic responses. J Allergy Clin Immunol. 2014;133:1162-74.

28. Lee S, Lee Y, Hong K, Hong J, Bae S, Choi J, Jet al. Effect of recombinant a1-antitrypsin Fc-fused (AAT-Fc)protein on the inhibition of inflammatory cytokine production and streptozotocin-induced diabetes. Mol Med. 2013;19: 65-71.

29. Shin YS, Takeda K, Shiraishi Y, Jeong YY, Domenico J, Jia Y, et al. Microbial heat shock protein 65 attenuates airway hyperresponsiveness and inflammation by modulating the function of dendritic cells. J Immunol. 2012;189:3404-10.

30. Stone PJ, Lucey EC, Calore JD, McMahon MP, Snider GL, Franzblau C. Defenses of the hamster lung against human neutrophil and porcine pancreatic elastase. Respiration. 1988:54:1-15.

31. Chapman KR, Burdon JG, Piitulainen E, Sandhaus RA, Seersholm N, Stocks $J M$, et al. Intravenous augmentation treatment and lung density in severe a1 antitrypsin deficiency (RAPID): a randomised, double-blind, placebocontrolled trial. Lancet. 2015;386:360-8.
32. Petrache I, Fijalkowska I, Zhen L, Medler TR, Brown E, Cruz P, et al. A novel antiapoptotic role for alpha1-antitrypsin in the prevention of pulmonary emphysema. Am J Respir Crit Care Med. 2006;173:1222-8.

33. Churg A, Wang RD, Xie C, Wright JL. Alpha-1-antitrypsin ameliorates cigarette smoke-induced emphysema in the mouse. Am J Respir Crit Care Med. 2003;168:199-207.

34. Pemberton PA, Kobayashi D, Wilk BJ, Henstrand JM, Shapiro SD, Barr PJ. Inhaled recombinant alpha 1-antitrypsin ameliorates cigarette smokeinduced emphysema in the mouse. COPD. 2006;3:101-8.

35. Forey BA, Thornton AJ, Lee PN. Systematic review with meta-analysis of the epidemiological evidence relating smoking to COPD, chronic bronchitis and emphysema. BMC Pulm Med. 2011;11:36.

36. Barnes PJ, Burney PG, Silverman EK, Celli BR, Vestbo J, Wedzicha JA, et al. Chronic obstructive pulmonary disease. Nat Rev Dis Primers. 2015;1:15076.

37. Criner GJ, Martinez FJ, Aaron S, Agusti A, Anzueto A, Bafadhel M, et al. Current controversies in chronic obstructive pulmonary disease. A report from the global initiative for chronic obstructive lung disease scientific committee. Ann Am Thorac Soc. 2019;16:29-39.

38. Wang $Y, X u$ J, Meng $Y$, Adcock IM, Yao X. Role of inflammatory cells in airway remodeling in COPD. Int J Chron Obstruct Pulmon Dis. 2018;13:3341-8.

39. Sullivan AK, Simonian PL, Falta MT, Mitchell JD, Cosgrove GP, Brown $\mathrm{KK}$, et al. Oligoclonal CD4+ T cells in the lungs of patients with severe emphysema. Am J Respir Crit Care Med. 2005;172:590-6.

40. Lee SH, Goswami S, Grudo A, Song LZ, Bandi V, Goodnight-White S, et al. Antielastin autoimmunity in tobacco smoking-induced emphysema. Nat Med. 2007;13:567-9.

41. Bhavani S, Tsai CL, Perusich S, Hesselbacher S, Coxson H, Pandit L, et al. Clinical and immunological factors in emphysema progression Five-year prospective longitudinal exacerbation study of chronic obstructive pulmonary disease (LES-COPD). Am J Respir Crit Care Med. 2015;192:1171-8.

42. Faner R, Cruz T, Casserras T, López-Giraldo A, Noell G, Coca I, et al. Network analysis of lung transcriptomics reveals a distinct B-cell signature in emphysema. Am J Respir Crit Care Med. 2016;193:1242-53.

43. Houghton AM, Quintero PA, Perkins DL, Kobayashi DK, Kelley DG, Marconcini $L A$, et al. Elastin fragments drive disease progression in a murine model of emphysema. J Clin Invest. 2006;116:753-9.

44. Moreno JA, Ortega-Gomez A, Rubio-Navarro A, Louedec L, Ho-Tin-Noé B, Caligiuri G, et al. High-density lipoproteins potentiate a1-antitrypsin therapy in elastase-induced pulmonary emphysema. Am J Respir Cell Mol Biol. 2014:51:536-49.

45. Peters M, Peters K, Bufe A. Regulation of lung immunity by dendritic cells: Implications for asthma, chronic obstructive pulmonary disease and infectious disease. Innate Immun. 2019;25:326-36.

46. Demedts IK, Bracke KR, Van Pottelberge G, Testelmans D, Verleden GM, Vermassen FE, et al. Accumulation of dendritic cells and increased CCL2O levels in the airways of patients with chronic obstructive pulmonary disease. Am J Respir Crit Care Med. 2007:175:998-1005.

47. Freeman CM, Martinez FJ, Han MK, Ames TM, Chensue SW, Todt JC, et al. Lung dendritic cell expression of maturation molecules increases with worsening chronic obstructive pulmonary disease. Am J Respir Crit Care Med. 2009:180:1179-88.

48. Vassallo R, Walters PR, Lamont J, Kottom TJ, Yi ES, Limper AH. Cigarette smoke promotes dendritic cell accumulation in COPD; A lung tissue research consortium study. Respir Res. 2010;11:45.

49. Harada H, Imamura M, Okunishi K, Nakagome K, Matsumoto T, Sasaki O, et al. Upregulation of lung dendritic cell functions in elastase-induced emphysema. Int Arch Allergy Immunol. 2009;149(Suppl 1):25-30.

50. D'hulst Al, Vermaelen KY, Brusselle GG, Joos GF, Pauwels RA. Time course of cigarette smoke-induced pulmonary inflammation in mice. Eur Respir J. 2005:26:204-13

51. Vassallo R, Kroening PR, Parambil J, Kita H. Nicotine and oxidative cigarette smoke constituents induce immune-modulatory and pro-inflammatory dendritic cell responses. Mol Immunol. 2008;45:3321-9.

52. Botelho FM, Nikota JK, Bauer CM, Morissette MC, Iwakura Y, Kolbeck R, et al. Cigarette smoke-induced accumulation of lung dendritic cells is interleukin-1a-dependent in mice. Respir Res. 2012;13:81.

53. Kuang LJ, Deng TT, Wang Q, Qiu SL, Liang Y, He ZY, et al. Dendritic cells induce Tc1 cell differentiation via the CD40/CD40L pathway in mice 
after exposure to cigarette smoke. Am J Physiol Lung Cell Mol Physiol. 2016;311:L581-9.

54. Elshikha AS, Lu Y, Chen MJ, Akbar M, Zeumer L, Ritter A, et al. Alpha 1 antitrypsin inhibits dendritic cell activation and attenuates nephritis in a mouse model of lupus. PLoS ONE. 2016;11:e0156583.

55. Guttman O, Yossef R, Freixo-Lima G, Rider P, Porgador A, Lewis EC. a1-Antitrypsin modifies general NK cell interactions with dendritic cells and specific interactions with islet $\beta$-cells in favor of protection from autoimmune diabetes. Immunology. 2015;144:530-9.

56. Liu L. Pharmacokinetics of monoclonal antibodies and Fc-fusion proteins. Protein Cell. 2018:9:15-32.
57. Guilliams M, Bruhns P, Saeys Y, Hammad H, Lambrecht BN. The function of FCy receptors in dendritic cells and macrophages. Nat Rev Immunol. 2014;14:94-108.

58. Lomas DA. Does protease-antiprotease imbalance explain chronic obstructive pulmonary disease? Ann Am Thorac Soc. 2016;13(Suppl 2):S130-7.

\section{Publisher's Note}

Springer Nature remains neutral with regard to jurisdictional claims in published maps and institutional affiliations.
Ready to submit your research? Choose BMC and benefit from:

- fast, convenient online submission

- thorough peer review by experienced researchers in your field

- rapid publication on acceptance

- support for research data, including large and complex data types

- gold Open Access which fosters wider collaboration and increased citations

- maximum visibility for your research: over $100 \mathrm{M}$ website views per year

At BMC, research is always in progress.

Learn more biomedcentral.com/submissions 